\title{
Assessment of transvalvular flow jet angle in aortic dilation patients using 4D flow jet shear layer detection method
}

\author{
Julio Garcia ${ }^{1 *}$, Michael Mark1 ${ }^{1,2}$, Pim van Ooij ${ }^{1}$, Susanne Schnell', Jeremy D Collins ${ }^{1}$, SC Malaisrie ${ }^{3}$, James C Carr ${ }^{1}$, \\ Alex J Barker ${ }^{1}$
}

From 17th Annual SCMR Scientific Sessions

New Orleans, LA, USA. 16-19 January 2014

\section{Background}

Patients with aortic dilation often present an eccentric transvalvular flow jet. The angle of the flow jet from the aorta centerline, or the flow jet angle (FJA), has been reported as a risk factor in bicuspid aortic valve patients [1]. In recent studies we introduced a the jet shear layer detection (JSLD) method for the automated characterization of transvalvular flow structure across the aortic valve $[2,3]$. The objective of this study was to evaluate FJA in patients with aortic dilation using the 3D JSLD structure obtained from 4D flow MRI.

\section{Methods}

This study included 40 patients with aortic dilation and aortic tricuspid valves participants (age $=58 \pm 16$ years, female $=11$, aortic stenosis $=10)$. Mid-ascending aorta (MAA) diameter and transvalvular peak velocity (Vpeak) were used to assess aortic dilation, aortic stenosis severity (AS, Vpeak $>2 \mathrm{~m} / \mathrm{s}$ ), and classify patients into four groups: Group 1 (MAA $<35 \mathrm{~mm}$ ); Group 2 (35 mm $<$ MAA $<45 \mathrm{~mm}$ ); Group 3 (MAA $>35$ $\mathrm{mm})$; Group 4 (MAA $>35 \mathrm{~mm}$ and $\mathrm{AS})$. 4D flow MRI was performed at $1.5 \mathrm{~T}$ and $3 \mathrm{~T}$ systems with full thoracic aorta volume coverage in a sagittal oblique slab (spatial resolution $=2.5 \times 2.1 \times 3.2 \mathrm{~mm} \mathrm{3}$; temporal resolution $=40-50 \mathrm{~ms}$ ). $4 \mathrm{D}$ flow data were used to compute a PC-MRA image and aorta volume segmentation was performed using Mimics (Materialise, Leuven, Belgium). The isolated aorta segmentation was used to automatically compute the vessel centerline, to mask 4D flow data, and compute 3D JSLD structure using Matlab (Natick, MA, USA). FJA workflow is summarized on Figure 1.

\section{Results}

Patient characteristics and measurements are presented in Table 1. A significant difference between groups was observed for age $(\mathrm{p}<0.05)$, Vpeak $(\mathrm{p}<0.001)$ and FJA $(\mathrm{p}<0.001)$ using an ANOVA test. Group 2-4 were older than Group 1. Group 4 presented higher Vpeak in comparison with Group 1-3 due to AS. When comparing FJA for defined group's population, significant differences were found between Group 2-4 vs. Group $1(\mathrm{p}<0.05)$ and Group 4 vs. Group 2 (p $<0.05$ ), see Figure 1D. Higher FJA was found in Group 3 and Group 4. Interestingly, the Pearson's correlation coefficient between Vpeak and FJA was $\mathrm{r}=0.54, \mathrm{p}<0.01$, and between ejection fraction and FJA was $\mathrm{r}=0.38, \mathrm{p}<0.05$.

\section{Conclusions}

The assessment of FJA can be automated using the volumetric information of 3D JSLD structure which relates the 3D JSLD structure to the aorta centerline, as obtained from 4D flow data. FJA was significantly higher in patients with severe aortic dilation and concomitant AS. Future longitudinal studies are needed to evaluate the impact of FJA in aortic dilation severity and altered flow patterns.

\section{Funding}

Grant support by NIH R01HL115828, NUCATS Dixon Award, AHA 13SDG14360004. CONACyT postdoctoral fellow grant (223355).

${ }^{1}$ Radiology, Northwestern University, Chicago, Illinois, USA

Full list of author information is available at the end of the article 


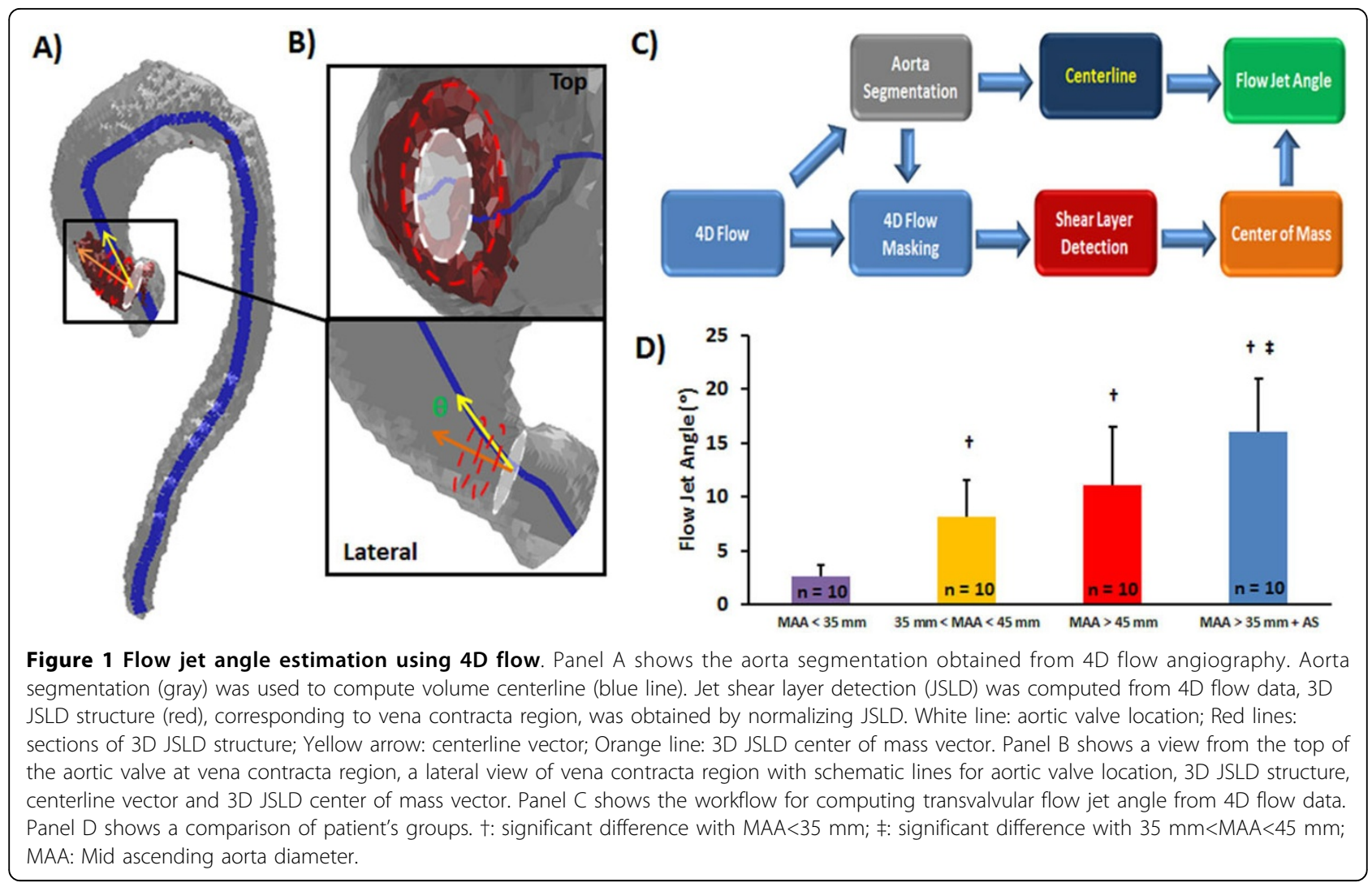

Table 1 Subject Characteristics

\begin{tabular}{|c|c|c|c|c|c|c|}
\hline & All & MAA $<35 \mathrm{~mm}$ & $35 \mathrm{~mm}<\mathrm{MAA}<45 \mathrm{~mm}$ & MAA $>45 \mathrm{~mm}$ & MAA $>35 \mathrm{~mm}+\mathrm{AS}$ & $\begin{array}{l}\text { p-value } \\
\text { ANOVA }\end{array}$ \\
\hline $\mathbf{n}$ & 40 & 10 & 10 & 10 & 10 & \\
\hline Age (years) & $58 \pm 16$ & $42 \pm 17$ & $63 \pm 11$ & $62 \pm 10$ & $63 \pm 14$ & $<0.05$ \\
\hline Female $(n)$ & 11 & 2 & 4 & 4 & 1 & NS \\
\hline Ejection Fraction (\%) & $59 \pm 7$ & $57 \pm 6$ & $59 \pm 8$ & $64 \pm 4$ & $60 \pm 6$ & NS \\
\hline Stroke Volume $(\mathrm{mL})$ & $91 \pm 30$ & $84 \pm 15$ & $84 \pm 21$ & $100 \pm 47$ & $96 \pm 30$ & NS \\
\hline Sinus of Valsalva Diameter (mm) & $41 \pm 5$ & $39 \pm 8$ & $41 \pm 3$ & $42 \pm 5$ & $39 \pm 4$ & NS \\
\hline Mid Ascending Aorta Diameter (mm) & $39 \pm 7$ & $30 \pm 4$ & $41 \pm 3$ & $47 \pm 2$ & $42 \pm 3$ & $<0.001$ \\
\hline Peak Velocity $(\mathrm{m} / \mathrm{s})$ & $1.6 \pm 0.9$ & $1.1 \pm 0.4$ & $1.3 \pm 0.3$ & $1.4 \pm 0.16$ & $2.9 \pm 0.9$ & $<0.001$ \\
\hline Flow Jet Angle(degrees) & $9 \pm 6$ & $3 \pm 1$ & $8 \pm 3$ & $11 \pm 5$ & $16 \pm 5$ & $<0.001$ \\
\hline
\end{tabular}

MAA: Mid Ascending Aorta; AS: Aortic Stenosis

\section{Authors' details}

${ }^{1}$ Radiology, Northwestern University, Chicago, Illinois, USA. ${ }^{2}$ Biomedical Engineering, Northwestern University, Chicago, Illinois, USA. ${ }^{3}$ Division of Cardiothoracic Surgery, Northwestern University, Chicago, Illinois, USA.

Published: 16 January 2014
doi:10.1186/1532-429X-16-S1-P47

Cite this article as: Garcia et al:: Assessment of transvalvular flow jet angle in aortic dilation patients using 4D flow jet shear layer detection method. Journal of Cardiovascular Magnetic Resonance 2014 16(Suppl 1): P47.

\section{References}

1. Della Corte A, et al: J Thorac Cardiovasc Surg 2011, 144(2):360-9.

2. Garcia, et al: J Cardiovasc Magn Reson 2012, 14:23.

3. Garcia, et al: J Cardiovasc Magn Reson 2013, 15(Suppl 1):p241. 